\title{
Multiobjective Optimization of Steering Mechanism for Rotary Steering System Using Modified NSGA-II and Fuzzy Set Theory
}

\author{
Hongtao Li, ${ }^{1}$ Wentie Niu, ${ }^{1}$ Shengli Fu, ${ }^{2}$ and Dawei Zhang ${ }^{1}$ \\ ${ }^{1}$ Key Laboratory of Mechanism Theory and Equipment Design of Ministry of Education, Tianjin University, Tianjin 300072, China \\ ${ }^{2}$ CNPC Bohai Drilling Engineering Company Limited, Tianjin 300457, China
}

Correspondence should be addressed to Wentie Niu; niuwentie@tju.edu.cn

Received 28 January 2015; Accepted 11 May 2015

Academic Editor: Mitsuhiro Okayasu

Copyright (c) 2015 Hongtao Li et al. This is an open access article distributed under the Creative Commons Attribution License, which permits unrestricted use, distribution, and reproduction in any medium, provided the original work is properly cited.

\begin{abstract}
Due to the complicated design process of gear train, optimization is a significant approach to improve design efficiency. However, the design of gear train is a complex multiobjective optimization with mixed continuous-discrete variables under numerous nonlinear constraints, and conventional optimization algorithms are not suitable to deal with such optimization problems. In this paper, based on the established dynamic model of steering mechanism for rotary steering system, the key component of which is a planetary gear set with teeth number difference, the optimization problem of steering mechanism is formulated to achieve minimum dynamic responses and outer diameter by optimizing structural parameters under geometric, kinematic, and strength constraints. An optimization procedure based on modified NSGA-II by incorporating dynamic crowding distance strategies and fuzzy set theory is applied to the multiobjective optimization. For comparative purpose, NSGA-II is also employed to obtain Pareto optimal set, and dynamic responses of original and optimized designs are compared. The results show the optimized design has better dynamic responses with minimum outer diameter and the response decay decreases faster. The optimization procedure is feasible to the design of gear train, and this study can provide guidance for designer at the preliminary design phase of mechanical structures with gear train.
\end{abstract}

\section{Introduction}

Gear trains are widely used in mechanical engineering for advantages of compact structure, high reliability, and large power transmission. However, the design of gear trains is a complex process, and the traditional design process of gear trains depends on the designer's intuition, experience, and skills, which is not satisfactory to the increasing demands for compactness, efficiency, and reliability in engineering application. Therefore, the optimization for gear trains has been a necessary process to solve the above problems at the preliminary design phase of gear trains, and many different optimization techniques have been reported in the literatures on gear trains.

The sequential quadratic programming (SQP) method was employed, respectively, by Bozca [1] and Huang et al. [2] to obtain a light-weight-gearbox structure by optimizing the geometric parameters of the gearbox. Chong et al. described a method for reduction of geometrical volume and meshing vibration of cylindrical gear pairs while satisfying strength and geometric constraints using a goal programming formulation [3]. Based on the random search method, Zarefar and Muthukrishnan investigated the optimization of helical gear design [4]. Ciavarella and Demelio investigated the optimization of stress concentration, specific sliding, and fatigue life of gears with numerical methods [5]. Huang et al. developed an interactive physical programming in order to optimize a three-stage spur gear reduction unit [6]. A Random-Simplex optimization algorithm was developed by Faggioni et al. for gear vibration reduction by means of profile modifications [7]. Based on min-max method combined with a direct search technique, Abuid and Ameen had done the optimization problem containing seven objective functions: gear volume, center distance, and five dynamic factors of shafts and gears [8]. Thompson et al. optimized minimum 
volume and surface fatigue of multistage spur gear reduction units by employing quasi-Newton method [9].

The mentioned optimization algorithms above are cataloged as conventional optimization techniques. Though they are efficient for some optimization problems in application, difficulties still exist in tackling some special problems with noncontinuous variables, complex constraints, and strongly nonlinear objectives. Therefore, some modern optimization methods such as genetic algorithm (GA) have been proposed to solve such problems in gear trains. By using the genetic algorithm, Mendi et al. investigated optimization of the modulus of spur gears, the diameters of shafts and rolling bearing [10]. Chong and Lee presented a design method to optimize the volume of two stage gear trains by using the genetic algorithm, which shows that the genetic algorithm is better than other conventional algorithms for solving the discrete, integer variable, and continuous problems [11]. Gologlu and Zeyveli introduced an automated preliminary design of gear drives by minimizing volume of gear trains using a genetic algorithm, and static and dynamic penalty functions were presented to the objective function for handling the design constraints [12]. Marcelin conducted optimum design of gears by GAs and penalty selection methods [13]. Buiga and Tudose investigated mass minimization design of a twostage coaxial helical speed reducer with genetic algorithms [14]. Ciglarič and Kidrič conducted automatic dynamic optimization of a gear pair by using genetic programming algorithm [15]. Bonori et al. performed profile modification optimization of spur gears by means of genetic algorithms, which aimed to reduce vibration and noise $[16,17]$.

However, most real-world optimization problems involve multiple objectives with mixed continuous-discrete variables under nonlinear constraints, and the conventional optimization techniques are not developed for such optimization problems in mind. Multiple objectives have to be reformulated as a single objective by weighted-sum approaches prior to optimization in practice, and the optimization program will be performed repeatedly by changing weighting factors to obtain Pareto optimal front. Meanwhile, the nonlinear constraints are handled by introducing penalty coefficients, and the inappropriate selection of penalty coefficients will lead to nonconvergence. Therefore, multiobjective evolutionary algorithms (MOEAs) as NSGA-II [18] have been developed to solve these problems. Deb and Jain demonstrated the use of NSGA-II in solving the original problem involving mixed discrete and real-valued parameters and more than one objective [19]. Sanghvi et al. investigated multiobjective optimization of a two-stage helical gear train by using NSGAII [20].

Though NSGA-II is considered as a successful multiobjective optimization algorithm, some drawbacks have been discovered as lack of uniform diversity in obtained nondominated solutions. To solve such problem, Luo et al. presented dynamic crowding distance (DCD) [21], which can be incorporated in NSGA-II as modified NSGA-II (MNSGAII). This optimization algorithm has never been applied in the design of gear trains.

In this paper, MNSGA-II is applied to multiobjective optimization of a novel steering mechanism for rotary steering

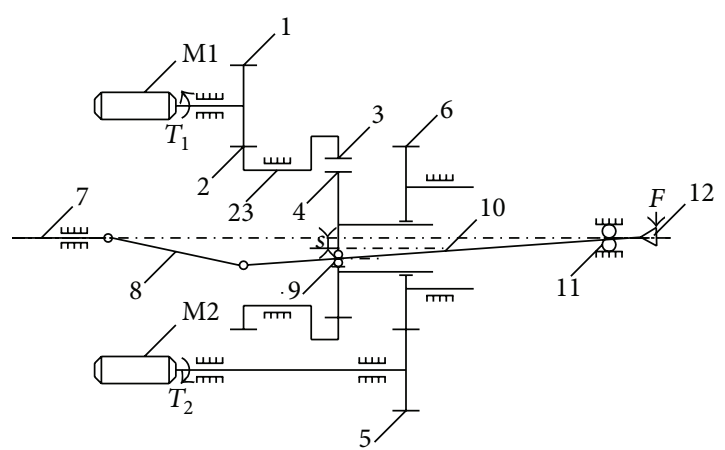

FIGURE 1: Schematic diagram of steering mechanism.

system (RSS), the key component of which is a planetary gear set with teeth number difference (PGSTND) [22]. This study aims to minimize the dynamic responses and outer diameter of steering mechanism with structural parameters as design variables subject to geometric, kinematic, and strength constraints. Based on the established dynamic model, the optimization problem is formulated, and both MNSGAII and NSGA-II are applied to the optimization problem. Meanwhile, in order to avoid human interference in selection of the best solution from Pareto optimal solutions when the objective preferences are absent, the best compromise solution is obtained by fuzzy set theory (FST), and the dynamic responses of optimized and original designs are compared and analyzed.

The rest of this paper is organized as follows: the problem formulation is established in Section 2. The optimization procedure based on MNSGA-II and FST is introduced and applied to the multiobjective optimization of steering mechanism for RSS in Section 3. Comparisons between results by MNSGA-II and NSGA-II are conducted, and the best compromise solution is obtained by FST and compared with the original design in Section 4. Finally, main conclusions are drawn in Section 5.

\section{Problem Formulation}

The studied object is a steering mechanism for RSS, the key components of which are a specially designed PGSTND and two servo motors [22]. The schematic diagram of steering mechanism is illustrated in Figure 1.

In Figure 1, M1 and M2 denote DC servo motors 1 and 2, respectively; 1 and 2, respectively, denote driving and driven gears for rotation; 3 denotes annulus gear; 23 denotes a parallel gear consisting of gear 2 and gear 3; 4 denotes planet gear; 5 and 6 , respectively, denote driving and driven gears for revolution; 7 denotes drill-string; 8 denotes universal joint; 9 denotes spherical plain bearing; 10 denotes drilling mandrel; 11 denotes spherical roller bearing; 12 denotes drill bit; $F$ denotes external excitation; $S$ denotes distance between rotating axis of gear 6 and eccentric axis of gear 4 .

In drilling process, the steering mechanism is inclined to fail due to the dynamic load, which is related not only to operation conditions but also to the structural dynamic 


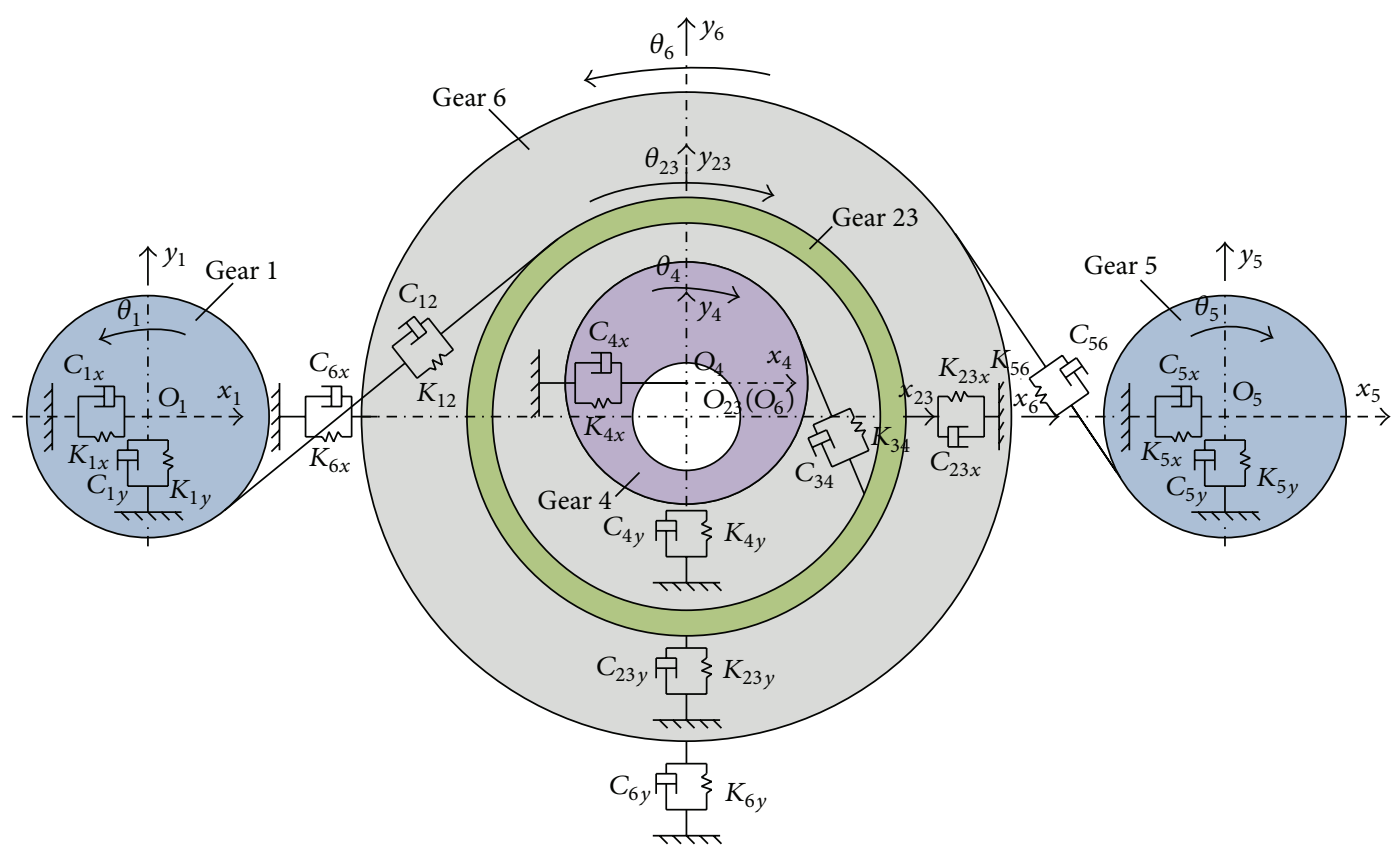

FIgURe 2: Dynamic model of steering mechanism.

characteristics of steering mechanism. Therefore, it is of significance to optimize the dynamic characteristics of steering mechanism for high reliability and long lifetime. Meanwhile, in consideration of the requirements for borehole size and annulus, the outer diameter of steering mechanism should be as small as possible. In this section, based on the established dynamic model of steering mechanism, the optimization problem is formulated for minimum dynamic responses and outer diameter of steering mechanism with structural parameters as design variables under geometric, kinematic, and strength constraints.

\subsection{Dynamic Modeling}

2.1.1. Dynamic Model. The lumped-parameter method is employed to establish the equivalent dynamic model of steering mechanism as shown in Figure 2. Each component has 3 degrees of freedom consisting of one angular displacement and two transverse displacements. Gear meshing interaction is modeled with time-varying meshing stiffness and damping. The backlash and dynamic transmission error are not considered in this study. The deformations of all bearings under load are represented by stiffness and damping between bodies and their housings in both $x$ and $y$ directions.

2.1.2. Equations of Motion (EOMs). By taking one angular displacement and two transverse displacements into consideration, EOMs of each gear are, respectively, derived by using Lagrange function as follows:

$$
\begin{aligned}
& I_{1} \ddot{\theta}_{1}+\left(C_{12} \dot{x}_{12}+K_{12}(t) x_{12}\right) r_{b 1}=T_{1}, \\
& m_{1} \ddot{x}_{1}+C_{1 x} \dot{x}_{1}+K_{1 x} x_{1} \\
& \quad+\left(C_{12} \dot{x}_{12}+K_{12}(t) x_{12}\right) \sin \alpha=0,
\end{aligned}
$$

$$
\begin{aligned}
& m_{1} \ddot{y}_{1}+C_{1 y} \dot{y}_{1}+K_{1 y} y_{1} \\
& +\left(C_{12} \dot{x}_{12}+K_{12}(t) x_{12}\right) \cos \alpha=0, \\
& I_{23} \ddot{\theta}_{23}-\left(C_{12} \dot{x}_{12}+K_{12}(t) x_{12}\right) r_{b 2} \\
& \quad+\left(C_{34} \dot{x}_{34}+K_{34}(t) x_{34}\right) r_{b 3}=0, \\
& m_{23} \ddot{x}_{23}+C_{23 x} \dot{x}_{23}+K_{23 x} x_{23} \\
& \quad-\left(C_{12} \dot{x}_{12}+K_{12}(t) x_{12}\right) \sin \alpha \\
& \quad+\left(C_{34} \dot{x}_{34}+K_{34}(t) x_{34}\right) \sin \left(\theta-\alpha_{34}\right)=0, \\
& m_{23} \ddot{y}_{23}+C_{23 y} \dot{y}_{23}+K_{23 y} y_{23} \\
& \quad-\left(C_{12} \dot{x}_{12}+K_{12}(t) x_{12}\right) \cos \alpha \\
& \quad+\left(C_{34} \dot{x}_{34}+K_{34}(t) x_{34}\right) \cos \left(\theta-\alpha_{34}\right)=0, \\
& \ddot{\theta}_{4}-\left(C_{34} \dot{x}_{34}+K_{34}(t) x_{34}\right) r_{b 4}=-F S, \\
& \quad+\left(C_{56} \dot{x}_{56}+K_{56}(t) x_{56}\right) \cos \alpha=0, \\
& m_{4} \ddot{x}_{4}+C_{4 x} \dot{x}_{4}+K_{4 x} x_{4} \\
& \quad+\left(C_{34} \dot{x}_{34}+K_{34}(t) x_{34}\right) \sin \alpha_{34}=0, \\
& m_{5} \ddot{y}_{5}+\left(C_{56} \dot{x}_{56}+K_{56}(t) x_{56}\right) r_{b 5}=T_{2}, \\
& m_{5} \ddot{x}_{5}+C_{5 x} \dot{x}_{5}+K_{5 x} x_{5} \\
& +\left(C_{4 y} \dot{y}_{4}+K_{4 y} \dot{x}_{34}+K_{34}(t) x_{56}\right) \sin \alpha=0, \\
& +K_{5 y} y_{5} \\
& \quad+\alpha_{34}=0,
\end{aligned}
$$




$$
\begin{aligned}
& I_{6} \ddot{\theta}_{6}-\left(C_{56} \dot{x}_{56}+K_{56}(t) x_{56}\right) r_{b 6} \\
& \quad+\left(C_{34} \dot{x}_{34}+K_{34}(t) x_{34}\right)\left(r_{b 3}-r_{b 4}\right)=0, \\
& m_{6} \ddot{x}_{6}+C_{6 x} \dot{x}_{6}+K_{6 x} x_{6}-\left(C_{56} \dot{x}_{56}+K_{56}(t) x_{56}\right) \sin \alpha \\
& \quad-\left(C_{34} \dot{x}_{34}+K_{34}(t) x_{34}\right) \sin \left(\theta-\alpha_{34}\right)=0, \\
& m_{6} \ddot{y}_{6}+C_{6 y} \dot{y}_{6}+K_{6 y} y_{6}-\left(C_{56} \dot{x}_{56}+K_{56}(t) x_{56}\right) \cos \alpha \\
& \quad-\left(C_{34} \dot{x}_{34}+K_{34}(t) x_{34}\right) \cos \left(\theta-\alpha_{34}\right)=0,
\end{aligned}
$$

where $x_{12}, x_{34}$, and $x_{56}$, respectively, denote the relative displacements of gear 1 and gear 2, gear 3 and gear 4 , gear 5 and gear 6 . The expressions are as follows:

$$
\begin{aligned}
x_{12}= & r_{b 1} \theta_{1}-r_{b 2} \theta_{23}+\left(x_{1}-x_{23}\right) \sin \alpha \\
& +\left(y_{1}-y_{23}\right) \cos \alpha, \\
x_{34}= & r_{b 3}\left(\theta_{23}+\theta_{6}\right)-r_{b 4}\left(\theta_{4}+\theta_{6}\right) \\
& +\left(x_{23}-x_{4}-x_{6}\right) \sin \left(\theta-\alpha_{34}\right) \\
& +\left(y_{23}-y_{4}-y_{6}\right) \cos \left(\theta-\alpha_{34}\right), \\
x_{56}= & r_{b 5} \theta_{5}-r_{b 6} \theta_{6}+\left(x_{5}-x_{6}\right) \sin \alpha+\left(y_{5}-y_{6}\right) \cos \alpha .
\end{aligned}
$$

In (1)-(2), $m_{i}$ denotes mass of gear $i ; x_{i}$ denotes displacement of gear $i$ in $x$ direction; $y_{i}$ denotes displacement of gear $i$ in $y$ direction; $I_{i}$ denotes inertia of gear $i$; $\alpha$ denotes pressure angle of each gear; $\alpha_{34}$ denotes meshing angle of gear 3 and gear $4 ; K_{i j}(t)$ and $C_{i j}$, respectively, denote timevarying meshing stiffness and damping between gear $i$ and gear $j$, which will be given in Section 2.1.3; $C_{i x}$ and $C_{i y}$, respectively, denote the supporting dampings of gear $i$ in $x$ and $y$ directions; $K_{i x}$ and $K_{i y}$ denote the supporting stiffness of gear $i$ in $x$ and $y$ directions, respectively; $T_{1}$ and $T_{2}$ denote input torques of $\mathrm{M} 1$ and $\mathrm{M} 2 ; \mathrm{F}$ denotes external excitation.

By substituting (2) into (1), the global EOMs of system are transformed in matrix form as

$$
\mathbf{M} \ddot{\mathbf{X}}+\mathbf{C} \dot{\mathbf{X}}+\mathbf{K}(t) \mathbf{X}=\mathbf{P},
$$

where $\mathbf{C}$ denotes damping matrix; $\mathbf{K}(t)$ denotes stiffness matrix; $\mathbf{P}$ denotes excitation vector; $\mathbf{M}$ and $\mathbf{X}$, respectively, represent mass matrix and displacement vector, which are given as

$$
\begin{aligned}
\mathbf{M}= & \operatorname{diag}\left[I_{1}, m_{1}, m_{1}, I_{23}, m_{23}, m_{23}, I_{4}, m_{4}, m_{4}, I_{5}, m_{5},\right. \\
& \left.m_{5}, I_{6}, m_{6}, m_{6}\right], \\
\mathbf{X}= & {\left[\theta_{1}, x_{1}, y_{1}, \theta_{23}, x_{23}, y_{23}, \theta_{4}, x_{4}, y_{4}, \theta_{5}, x_{5}, y_{5}, \theta_{6},\right.} \\
& \left.x_{6}, y_{6}\right]^{T} .
\end{aligned}
$$

\subsubsection{System Excitation}

(1) Meshing Stiffness. The meshing stiffness will fluctuate with time due to the periodic change of gear meshing. Meanwhile, the deformations of gear teeth are different from dedendum to addendum in meshing, which also causes the variation of meshing stiffness. The meshing stiffness can be formulated by sine expression as [23]

$$
K(t)=K_{m}+K_{a} \sin \left(\omega_{m} t+\tau\right),
$$

where $K_{m}$ and $K_{a}$, respectively, represent the average value of mesh stiffness and the amplitude of variable mesh stiffness; $\omega_{m}$ is meshing frequency and the expression is $\omega_{m}=\pi n z / 30$; $n, z$, and $\tau$ denote working speed, teeth number, and meshing phase angle, respectively.

(2) Meshing Damping. The expression of meshing damping is [23]

$$
C_{12}=2 \xi \sqrt{\frac{K_{m} m_{1} m_{2}}{m_{1}+m_{2}}},
$$

where $\xi, m_{1}$, and $m_{2}$ are, respectively, meshing damping coefficient, mass of driving gear, and driven gear.

2.2. Objective Functions. The structural damage mainly results from dynamic characteristics of steering mechanism, and the maximum transverse acceleration of each gear is chosen as the optimization objective:

$$
\begin{array}{r}
f_{i x \min }=a_{i x}, \\
f_{i y \min }=a_{i y}, \\
(i=1,23,4,5,6),
\end{array}
$$

where $a_{i x}=\ddot{x}_{i}$ is the maximum acceleration of gear $i$ in $x$ direction; $a_{i y}=\ddot{y}_{i}$ is the maximum acceleration of gear $i$ in $y$ direction; $\ddot{x}_{i}$ and $\ddot{y}_{i}$ can be obtained by solving (3) using Newmark- $\beta$ method.

Besides, in consideration of borehole size (the studied case is $121 / 4^{\prime \prime}$ ) and annulus, the outer diameter must be minimized for more drilling requirements on the condition of good dynamic performances

$$
f_{\text {Dmin }}=D \text {, }
$$

where $D$ is the outer diameter of steering mechanism.

2.3. Design Variables. Parameters with significant impact on objective functions are chosen as the design variables. However, increasing design variables lead to more timeconsuming iterations, so it is necessary to reduce design variables properly. The aim of this study is to optimize the dynamic characteristics and dimension of steering mechanism, which depend on the system parameters as mass, stiffness, damping, inertia, and external excitation according to (1). Meanwhile, these system parameters are determinate by the structural parameters of steering mechanism in essence. Therefore, teeth number of gear $i: z_{i}(i=1, \ldots, 6)$, modulus of gears $i$ and $j: m_{i j}(i j=12,34,56)$, width of gears $i$ and $j: b_{i j}(i j=12,34,56)$, diameter of mandrel: $d$, location parameter of steering point: $l_{1}$, and location parameter of 
TABLE 1: Design variables.

\begin{tabular}{lccccccccccccccc}
\hline Items & $z_{1}$ & $z_{2}$ & $z_{3}$ & $z_{4}$ & $z_{5}$ & $z_{6}$ & $\begin{array}{c}m_{12} \\
(\mathrm{~mm})\end{array}$ & $\begin{array}{c}m_{34} \\
(\mathrm{~mm})\end{array}$ & $\begin{array}{c}m_{56} \\
(\mathrm{~mm})\end{array}$ & $\begin{array}{c}b_{12} \\
(\mathrm{~mm})\end{array}$ & $\begin{array}{c}b_{34} \\
(\mathrm{~mm})\end{array}$ & $\begin{array}{c}b_{56} \\
(\mathrm{~mm})\end{array}$ & $\begin{array}{c}d \\
(\mathrm{~mm})\end{array}$ & $\begin{array}{c}l_{1} \\
(\mathrm{~m})\end{array}$ & $\begin{array}{c}l_{2} \\
(\mathrm{~m})\end{array}$ \\
\hline Lower & 17 & 20 & 25 & 21 & 17 & 20 & 1.5 & 3 & 1.5 & 30 & 30 & 30 & 80 & 0.3 & 0.2 \\
Upper & 32 & 51 & 56 & 52 & 32 & 51 & 4 & 5 & 4 & 70 & 70 & 70 & 120 & 0.62 & 0.42 \\
\hline
\end{tabular}

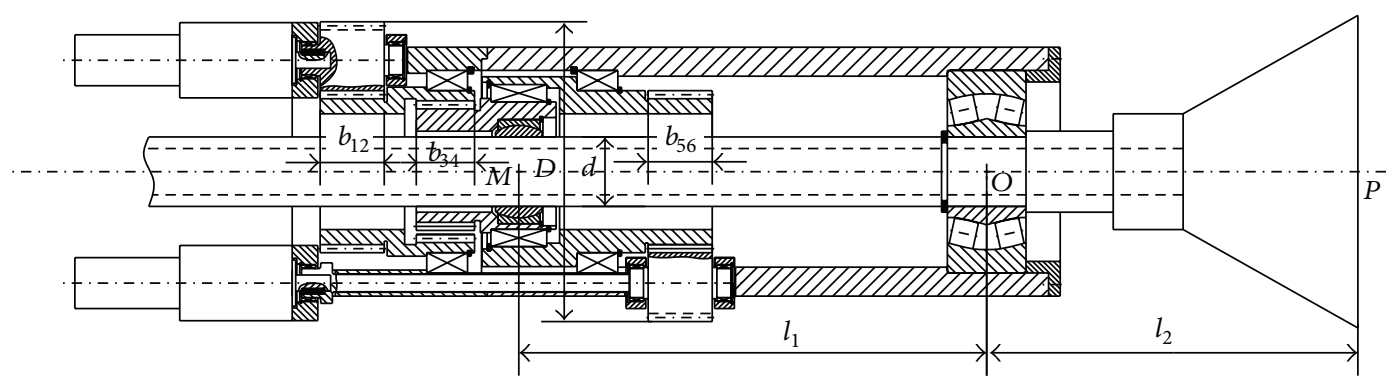

FIGURE 3: Structure of steering mechanism for RSS.

TABLE 2: Operating parameters.

\begin{tabular}{lccc}
\hline Parameters & $T_{1}(\mathrm{~N} \cdot \mathrm{m})$ & $T_{2}(\mathrm{~N} \cdot \mathrm{m})$ & $F(\mathrm{KN})$ \\
\hline Values & 50 & 50 & 20 \\
\hline
\end{tabular}

spherical roller bearing: $l_{2}$ are chosen as design variables, and the lower and upper limits of variables are listed in Table 1 based on mechanical design criterion and engineering experiences.

Dimensions of design variables in optimization formulation are illustrated in Figure 3.

Operating parameters of steering mechanism are listed in Table 2.

\subsection{Constraints}

(1) Number of Teeth. Due to the application of PGSTND, the teeth number difference of inner meshing pair should be limited in a certain range according to the mechanical design criterion, and all teeth numbers must be integers

$$
\begin{aligned}
1 & \leq z_{3}-z_{4} \leq 4 \\
z_{i} & =\text { Integer } \quad(i=1, \ldots, 6) .
\end{aligned}
$$

(2) Contact Ratio. In order to ensure the continuity and stability of gear transmission, the contact ratio of each meshing pair is limited as

$$
1.1 \leq \varepsilon_{i j} \leq 2.2
$$

where $\varepsilon_{i j}(i j=12,34,56)$ denotes the contact ratio of gear $i$-gear $j$ pair.

(3) Tooth Thickness at Tip Cylinder. To ensure the strength of gear teeth at tip cylinder, tooth thickness at tip cylinder should be constrained during machining process [24]

$$
0.4 m_{t i}-S_{a i} \leq 0
$$

where $S_{a i}(i=1, \ldots, 6)$ is the tooth thickness of gear $i$ at tip cylinder.

(4) Profile Modification Coefficient. PGSTND is applied in steering mechanism, and profile modification coefficients should be limited to avoid interference of gear 3 and gear 4

$$
\begin{aligned}
& -0.5 \leq x_{n 3} \leq 0.5, \\
& -0.5 \leq x_{n 4} \leq 0.5,
\end{aligned}
$$

where $x_{n 3}$ and $x_{n 4}$ are, respectively, profile modification coefficients of gear 3 and gear 4 .

(5) Gear Strength. Since gear failures usually exist in forms of crack and pitting corrosion, it is essential to check the contacting strength and bending strength of gear teeth as follows [25].

Contact strength:

$$
\sigma_{H}=\frac{1070}{a} \sqrt{\frac{(i+1)^{3} K_{d} T}{b i}} \leq\left[\sigma_{H}\right],
$$

where $\sigma_{H}$ denote maximum contact strength; $a$ is centre distance of meshing pair; $i$ denotes transmission ratio of meshing pair; $K_{d}$ is dynamic load coefficient $\left(K_{d}\right.$ is equal to $1.3)$; $T$ is torque of pinion in meshing pair; $\left[\sigma_{H}\right]$ is allowable contact stress.

Bending strength:

$$
\sigma_{F}=\frac{2 K_{d} T_{1}}{b d_{1} m y_{F}} \leq\left[\sigma_{F}\right]
$$

where $\sigma_{F}$ denotes maximum bending strength; $d_{1}$ denotes pitch diameter of pinion in a meshing pair; $\left[\sigma_{F}\right]$ denotes allowable bending stress; $y_{F}$ denotes tooth form factor.

(6) Outer Diameter. Based on the borehole size and annulus requirements, the outer diameter of steering mechanism is constrained as

$$
D \leq 280 \mathrm{~mm} .
$$




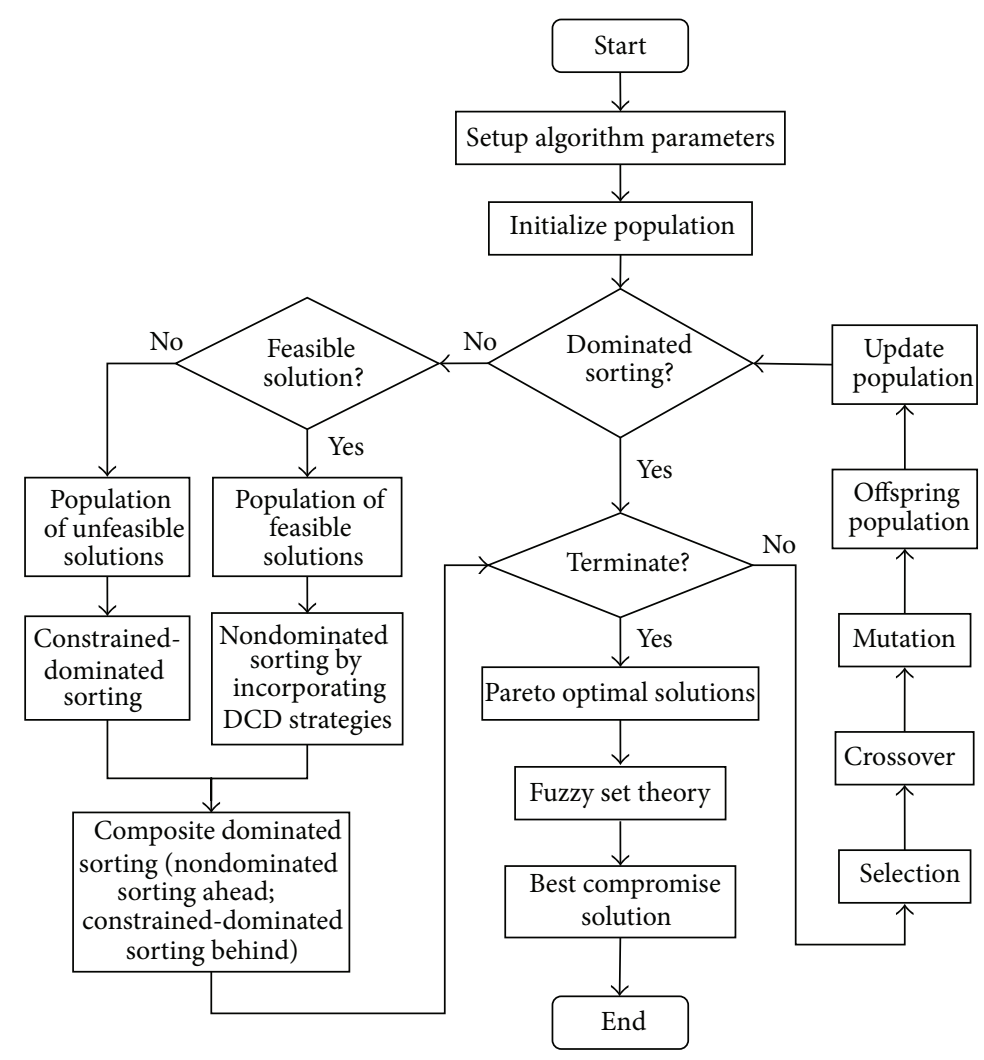

FIGURE 4: Flowchart of optimization procedure based on MNSGA-II and FST.

(7) Alternating Stress of Mandrel. The mandrel suffers alternating stress during operation, and the maximum bending stress should be limited to avoid destruction:

$$
\sigma_{\max } \leq[\sigma]
$$

where $\sigma_{\max }$ is maximum bending stress and $[\sigma]$ is allowable bending stress.

(8) Torque Constraint. To meet the requirement for cutting force, the enlarged input torque must be enough to conquer the load torque:

$$
i T_{1}=\frac{0.5 S F l_{2}}{l_{1}} .
$$

(9) Build-Up Rate. To meet the requirements of build-up rate that $k$ is equal to $8^{\circ} / 30 \mathrm{~m}$, and build-up rate is constrained by the expression in [22]:

$$
10.7 \beta=8,
$$

where $\beta=\arctan \left(2 S / l_{1}\right)$ is the steering angle of steering mechanism.

2.5. Optimization Problem Formulation. Based on the above analysis, the optimization problem of steering mechanism is a multiobjective optimization with mixed continuousdiscrete variables under nonlinear constraints; that is, the minimizations of dynamic responses and outer diameter of steering mechanism are investigated by selecting the structural parameters of PGSTND and mandrel subject to some structural and stress constraints. In general, the optimization problem can be formulated as follows:

$$
\begin{array}{cl}
\text { Minimize } & \left\lfloor f_{i x \min }(x), f_{i y \min }(x), f_{D}(x)\right\rfloor \\
\text { Subject to: } & h_{v}(\mathbf{x})=0 \\
& \left.g_{u}(\mathbf{x}) \leq 0,1,23,4,5,6\right)
\end{array}
$$

where $h_{v}(\mathbf{x})$ is equal constraint function; $g_{u}(\mathbf{x})$ is unequal constraint function; $v, u$ are, respectively, the numbers of equal and unequal constraint functions; $\mathbf{x}$ is a set of design variables and given by

$$
\begin{aligned}
& \mathbf{x} \\
& =\left[\begin{array}{lllllllllllllll}
z_{1} & z_{2} & z_{3} & z_{4} & z_{5} & z_{6} & m_{12} & m_{34} & m_{56} & b_{12} & b_{34} & b_{56} & d & l_{1} & l_{2}
\end{array}\right]^{T} \text {. }
\end{aligned}
$$

The optimization procedure based on MNSGA-II and FST is applied to solve this optimization problem, and the optimization procedure and results will be, respectively, demonstrated in Sections 3 and 4.

\section{Optimization Procedure Based on MNSGA-II and FST}

3.1. Optimization Flowchart. The optimization procedure based on MNSGA-II and FST is shown in Figure 4. The core 
TABLE 3: Algorithm parameters.

\begin{tabular}{lcccc}
\hline Parameters & $\begin{array}{c}\text { Population } \\
\text { size }\end{array}$ & $\begin{array}{c}\text { Number of } \\
\text { generation }\end{array}$ & $\begin{array}{c}\text { Crossover } \\
\text { probability }\end{array}$ & $\begin{array}{c}\text { Mutation } \\
\text { rate }\end{array}$ \\
\hline Values & 300 & 150 & 0.9 & 0.1 \\
\hline
\end{tabular}

of optimization is constrained-dominated sorting algorithm. Meanwhile, the DCD strategies are incorporated to improve the uniformity of Pareto front.

In traditional design, the best solution in Pareto optimal solutions is usually selected based on decision maker's experience and skills, which is subjected to human preference. To deal with the drawbacks, FST is applied to obtain the best comprise solution from Pareto optimal solutions, in which empirical design is replaced by theoretical design.

The detailed introductions of MNSGA-II and FST will be made in Sections 3.2 and 3.3.

\subsection{Introduction of MNSGA-II}

3.2.1. Algorithm Initialization and Genetic Operators. In MNSGA-II, the algorithm parameters include population size, number of generation, crossover probability, and mutation rate, which can be determinate by usual methods. Based on the optimization problem formulation in Section 2, the algorithm parameters are listed in Table 3. Meanwhile, binary encoding is used to initialize population with discrete and continuous variables [26].

Selection is the first genetic operator which guarantees that individuals with excellent genes are selected from parent population, and binary tournament selection is chosen for calculation in MNSGA-II. Crossover and mutation are the genetic operators to maintain the diversity of population by producing offspring individuals, and uniform crossover and single-point mutation are, respectively, applied for mutation and mutation in this study [19].

3.2.2. Nondominated Sorting by Incorporating DCD Strategies. Nondominated sorting is still the core of MNSGA-II to determinate the distribution of Pareto optimal solutions. Owing to the particularity of nonlinear constraints in this study, the constrained-dominated sorting [18] and the modified nondominated sorting by incorporating DCD strategies are used for the optimization.

The modified nondominated sorting by incorporating DCD strategies is as follows.

In conventional NSGA-II approach, the solutions in the same rank are sorted based on crowding distance in nondominated sorting, and the crowding distance is calculated as

$$
\mathrm{CD}_{i}=\frac{1}{r} \sum_{k=1}^{r}\left|f_{i+1}^{k}-f_{i-1}^{k}\right|
$$

where $\mathrm{CD}_{i}$ is crowding distance of the $i$ th solution; $r$ is the number of objectives; $f_{i}^{k}$ is the $k$ th objective value of the $i$ th solution.

However, nondominated sorting using the above crowding distance has drawback of weak uniform diversity in obtained Pareto optimal solutions. DCD strategies are incorporated in currently used NSGA-II to deal with the mentioned problem, and DCD of the $i$ th solution is expressed as [21]

$$
\operatorname{DCD}_{i}=\frac{\mathrm{CD}_{i}}{\log \left(1 / V_{i}\right)},
$$

where $\mathrm{DCD}_{i}$ denotes the dynamic crowding distance of the $i$ th solution and $V_{i}$ is expressed as

$$
V_{i}=\frac{1}{r} \sum_{k=1}^{r}\left(\left|f_{i+1}^{k}-f_{i-1}^{k}\right|-\mathrm{CD}_{i}\right)^{2} .
$$

$V_{i}$ is the variance of CDs of individuals which are neighbors of the $i$ th solution, and it gives some information about the difference degree of CD in different objectives.

In addition, the nondominated sorting algorithm is changed due to the incorporation of DCD strategies. Suppose population size is $N$, the $i$ th generation of nondominated sorting set is $Q(t)$, and the size of $Q(t)$ is $M$; then $M-N$ solutions are wiped off, and procedures are performed as follows [21].

Step 1. If $|Q(t)| \leq N$, go to Step 5; else keep on.

Step 2. Calculate all solutions' DCD in the $Q(t)$ based on (22).

Step 3. Sort $Q(t)$ based on solutions' DCD.

Step 4. Wipe off a solution which has the lowest DCD in the $Q(t)$.

Step 5. If $|Q(t)| \leq N$, stop population maintenance; else go Step 2 and keep on.

It can be seen that one solution is wiped off every time, and all solutions' DCD in the $Q(t)$ will be recalculated. Therefore, the diversity of modified nondominated sorting can be maintained, and a Pareto front with high uniformity is also obtained.

3.3. Fuzzy Set Theory. For Pareto optimal solutions with $N_{\text {obj }}$ objectives and $M$ solutions, a membership function $\mu_{i}$ denotes the $i$ th objective function of a solution in Pareto optimal solutions, which is defined as [27]

$$
\mu_{i}= \begin{cases}1, & F_{i} \leq F_{i}^{\min } \\ \frac{F_{i}^{\max }-F_{i}}{F_{i}^{\max }-F_{i}^{\min },} & F_{i}^{\min } \leq F_{i} \leq F_{i}^{\max } \\ 0, & F_{i} \geq F_{i}^{\max },\end{cases}
$$

where $F_{i}^{\max }$ and $F_{i}^{\mathrm{min}}$, respectively, denote the maximum and minimum values of the $i$ th objective function. For each nondominated solution $k$, the normalized membership function $\mu^{k}$ is expressed as

$$
\mu^{k}=\frac{\sum_{i=1}^{N_{\mathrm{obj}}} \mu_{i}^{k}}{\sum_{j=1}^{M} \sum_{i=1}^{N_{\mathrm{obj}}} \mu_{i}^{j}} .
$$


TABLE 4: Comparisons between original and optimized designs.

\begin{tabular}{lccccccccccccccc}
\hline Items & $z_{1}$ & $z_{2}$ & $z_{3}$ & $z_{4}$ & $z_{5}$ & $z_{6}$ & $\begin{array}{c}m_{12} \\
(\mathrm{~mm})\end{array}$ & $\begin{array}{c}m_{34} \\
(\mathrm{~mm})\end{array}$ & $\begin{array}{c}m_{56} \\
(\mathrm{~mm})\end{array}$ & $\begin{array}{c}b_{12} \\
(\mathrm{~mm})\end{array}$ & $\begin{array}{c}b_{34} \\
(\mathrm{~mm})\end{array}$ & $\begin{array}{c}b_{56} \\
(\mathrm{~mm})\end{array}$ & $\begin{array}{c}D \\
(\mathrm{~mm})\end{array}$ & $\begin{array}{c}l_{1} \\
(\mathrm{~m})\end{array}$ & $\begin{array}{c}l_{2} \\
(\mathrm{~m})\end{array}$ \\
\hline Original & 17 & 38 & 33 & 30 & 17 & 38 & 3.5 & 3.5 & 3.5 & 50 & 50 & 50 & 80 & 0.601 & 0.367 \\
Optimized & 18 & 43 & 37 & 35 & 22 & 37 & 3 & 4.5 & 3 & 45 & 63 & 47 & 81 & 0.564 & 0.297 \\
\hline
\end{tabular}

TABLE 5: Comparisons of dynamic responses and outer diameter in original and optimized designs.

\begin{tabular}{lccccccccccc}
\hline Items & $\begin{array}{c}a_{1 x} \\
\left(\mathrm{~m} / \mathrm{s}^{2}\right)\end{array}$ & $\begin{array}{c}a_{1 y} \\
\left(\mathrm{~m} / \mathrm{s}^{2}\right)\end{array}$ & $\begin{array}{c}a_{23 x} \\
\left(\mathrm{~m} / \mathrm{s}^{2}\right)\end{array}$ & $\begin{array}{c}a_{23 y} \\
\left(\mathrm{~m} / \mathrm{s}^{2}\right)\end{array}$ & $\begin{array}{c}a_{4 x} \\
\left(\mathrm{~m} / \mathrm{s}^{2}\right)\end{array}$ & $\begin{array}{c}a_{4 y} \\
\left(\mathrm{~m} / \mathrm{s}^{2}\right)\end{array}$ & $\begin{array}{c}a_{5 x} \\
\left(\mathrm{~m} / \mathrm{s}^{2}\right)\end{array}$ & $\begin{array}{c}a_{5 y} \\
\left(\mathrm{~m} / \mathrm{s}^{2}\right)\end{array}$ & $\begin{array}{c}a_{6 x} \\
\left(\mathrm{~m} / \mathrm{s}^{2}\right)\end{array}$ & $\begin{array}{c}a_{6 y} \\
\left(\mathrm{~m} / \mathrm{s}^{2}\right)\end{array}$ & $\begin{array}{c}D \\
(\mathrm{~m})\end{array}$ \\
\hline Original & 1.51 & 4.14 & 0.94 & 2.63 & 0.25 & 0.55 & 1.51 & 4.15 & 1.329 & 2.108 & 0.258 \\
Optimized & 1.43 & 3.92 & 0.56 & 1.63 & 0.23 & 0.52 & 1.41 & 3.89 & 1.00 & 1.62 & 0.240 \\
Difference (\%) & 5.41 & 5.40 & 40.10 & 37.96 & 6.02 & 5.38 & 6.28 & 6.27 & 24.76 & 23.14 & 6.98 \\
\hline
\end{tabular}

In (25), larger $\mu^{k}$ indicates better compromise solution. Therefore, a priority list of nondominated solutions is obtained by descending sort of $\mu^{k}$, and it is beneficial for decision maker to choose the best compromise solution in Pareto optimal solutions.

\section{Results and Discussions}

4.1. Comparison between Optimized Results. In order to evaluate the performance of MNSGA-II for optimization problem of steering mechanism, both MNSGA-II and NSGAII are used to solve the optimization, and Pareto fronts are illustrated in Figure 5.

As shown in Figure 5(a), the competitive relationship between maximum accelerations of gear 1 in $x$ and $y$ directions is linear, and the distribution of Pareto optimal solutions by MNSGA-II is more uniform than that by NSGA-II. The same phenomena also can be discovered in the competitive relationships between maximum accelerations of gear 4 and gear 5 in $x$ and $y$ directions as shown in Figures 5(c) and 5(d). The competitive relationship between maximum accelerations of gear 23 in $x$ and $y$ directions is approximatively linear as shown in Figure 5(b). Meanwhile, the distribution of Pareto optimal solutions by MNSGA-II is more uniform than that by NSGA-II. The same phenomena also can be discovered in the competitive relationship between maximum accelerations of gear 6 in $x$ and $y$ directions as shown in Figure 5(e).

Based on the above analysis, MNSGA-II can avoid phenomena that some parts of the Pareto fronts are too crowded and some parts are sparseness. The uniformity of Pareto fronts is improved, which indicates that the MNSGA-II is feasible for optimization problem of steering mechanism.

4.2. Pareto Optimal Solutions. In order to reveal the variation trends of all objectives directly, the Pareto optimal solutions obtained by MNSGA-II are shown in Figure 6, in which each vertical axis represents an objective and each broken line represents a solution. As illustrated in Figure 6, the maximum accelerations of each gear in $x$ and $y$ directions appear in linear or approximately linear relationship as depicted in Section 4.1. However, the competitive relationship between maximum acceleration of gear 1 in $y$ direction and that of gear 23 in $x$ direction is irregular, and the same phenomena can be reflected in maximum accelerations of gear 23 in $y$ direction and gear 4 in $x$ direction, gear 4 in $y$ direction and gear 5 in $x$ direction, and gear 5 in $y$ direction and gear 6 in $x$ direction, which indicate that the effect of structural parameters on the dynamics of steering mechanism is complex. Therefore, it is significant to optimize the dynamics of steering mechanism. Meanwhile, due to the conflicts between objectives, it is difficult for designer to select the best solution from Pareto optimal solutions, and it is also subjected to human preference. In this study, FST in Section 3.3 is applied to select the best compromise solution from Pareto optimal solutions, which avoid the effect of human behaviors.

The best compromise solution obtained by FST is shown by green broken line in Figure 6, and the red broken line represents the dynamic characteristics of original design. The comparisons between original and optimized designs are shown in Table 4.

Based on the analysis of dynamic characteristics shown in Figure 6, the comparisons of maximum accelerations and outer diameter of original and optimized designs are shown in Table 5. The maximum accelerations of all gears decrease in different extent, and the maximum accelerations of gear 23 decrease from $0.94 \mathrm{~m} / \mathrm{s}^{2}$ to $0.56 \mathrm{~m} / \mathrm{s}^{2}$ by $40.1 \%$ in $x$ direction and from $2.63 \mathrm{~m} / \mathrm{s}^{2}$ to $1.63 \mathrm{~m} / \mathrm{s}^{2}$ by $37.96 \%$ in $y$ direction. In addition, the outer diameter of steering mechanism decreases from $0.258 \mathrm{~m}$ to $0.24 \mathrm{~m}$ by $6.98 \%$. Optimization results indicate that not only are the dynamic characteristics improved but also the outer diameter is decreased, which can meet more requirements on borehole size.

4.3. Comparisons between Responses in Original and Optimized Designs. To reflect the response variance of each gear in original and optimized designs, the response curves of each gear are depicted in Figures 7-11 in which (a) and (b), respectively, represent responses in $x$ and $y$ directions. The acceleration amplitudes in $x$ and $y$ directions decrease in different degrees as shown in Figures 7-11 and the response decays get faster as shown in Figures 8, 9, and 11, which indicate that the responses are improved after optimization and the optimization procedure is effective for the steering mechanism. 


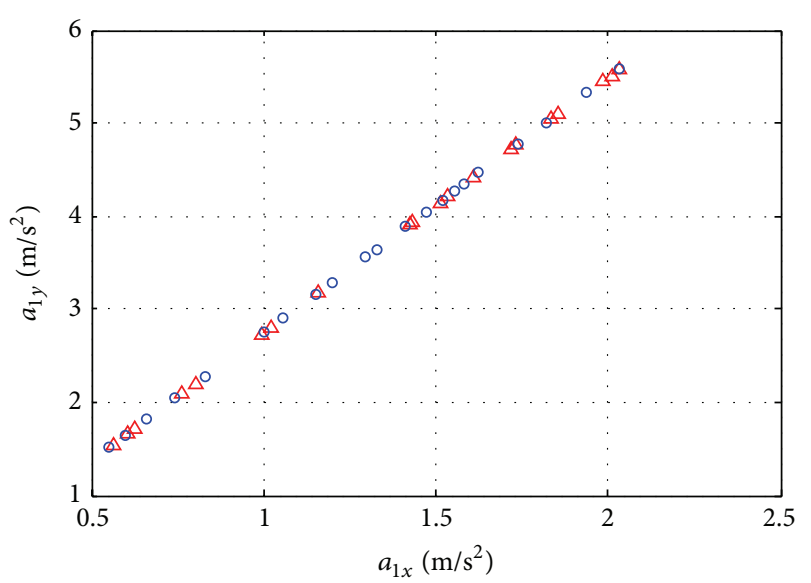

(a)

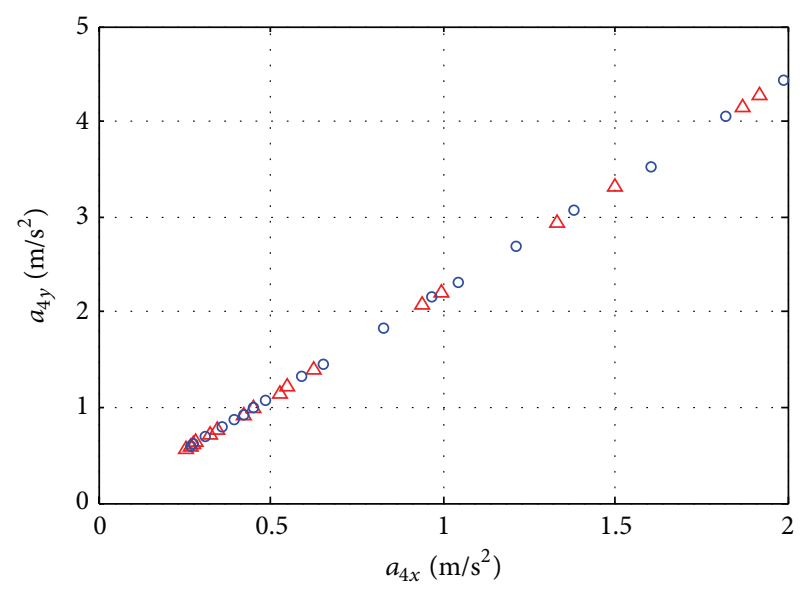

(c)

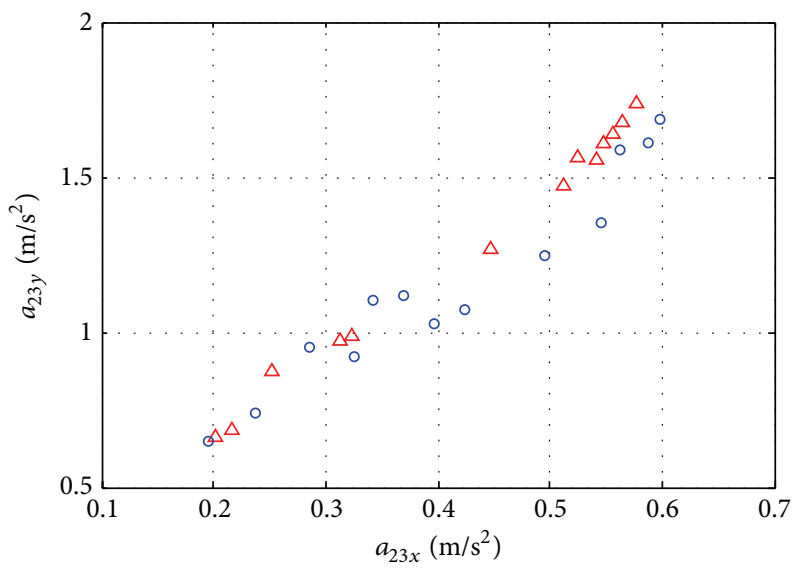

(b)

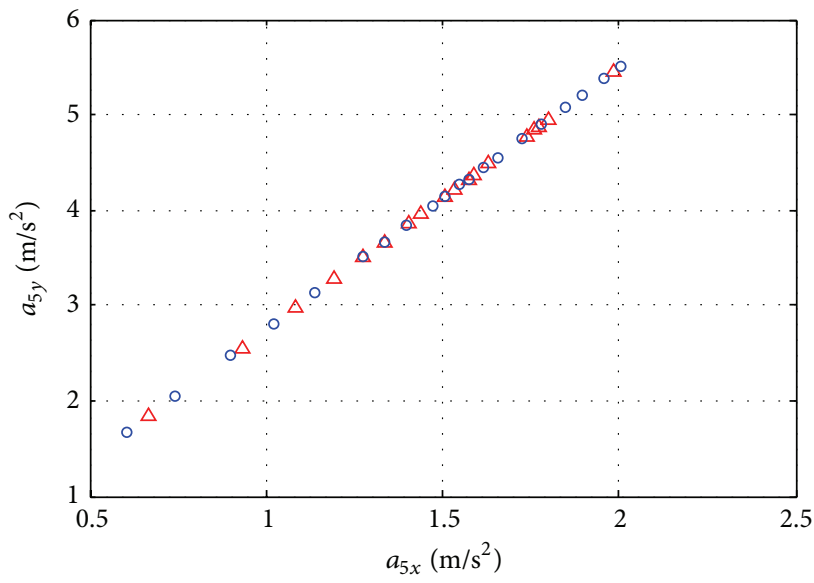

(d)

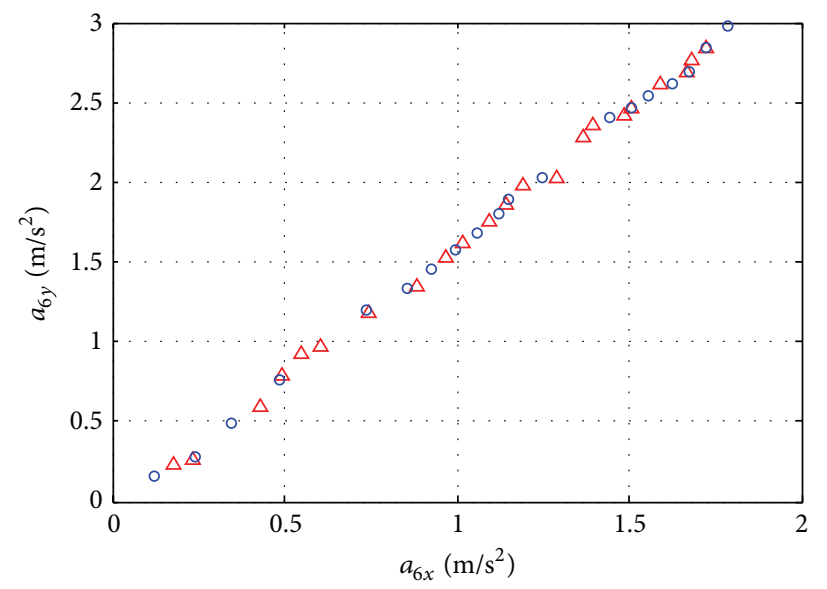

(e)

FIGURE 5: Pareto fronts for different objectives ( $\triangle$ : NSGA-II; O: MNSGA-II).

\section{Conclusions}

The design of gear train is a complex multiobjective optimization with mixed continuous-discrete variables under numerous nonlinear constraints. In this paper, based on the dynamic model of steering mechanism in which the key component is a PGSTND, the optimization problem of steering mechanism is investigated by the optimization procedure based on MNSGA-II and FST, and conclusions can be drawn as follows:

(1) For multiobjective optimization of steering mechanism for RSS, MNSGA-II can improve uniformity of Pareto fronts compared with NSGA-II. 


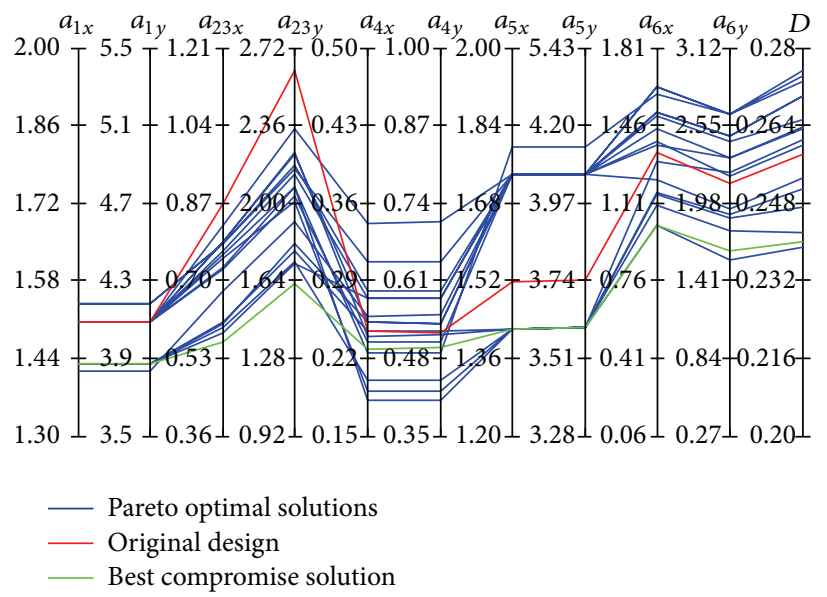

Figure 6: Pareto optimal solutions for all objectives (units: $a\left(\mathrm{~m} / \mathrm{s}^{2}\right) ; D(\mathrm{~m})$ ).

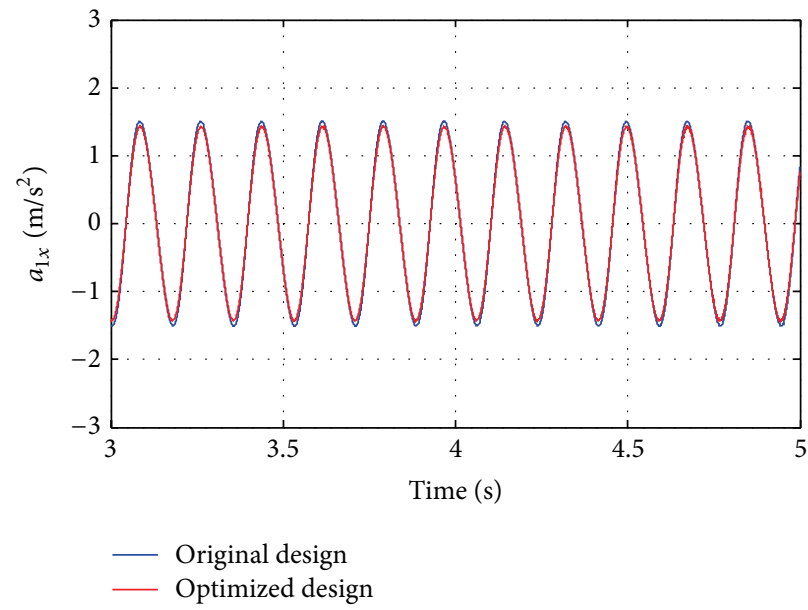

(a)

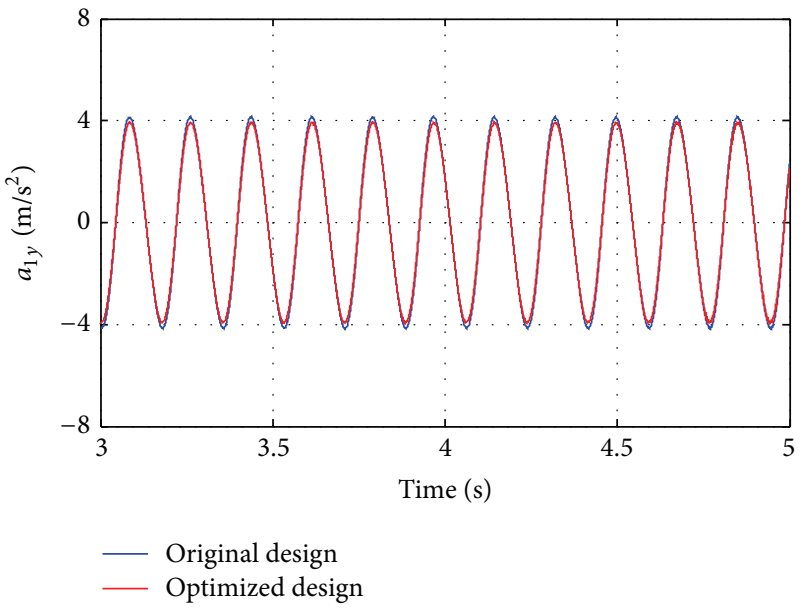

(b)

FIGURE 7: Responses of gear 1 in original and optimized designs.

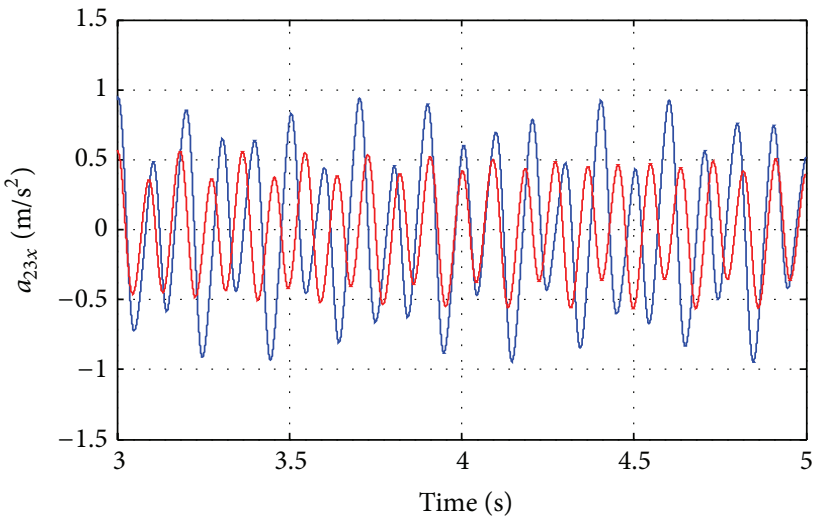

- Original design Optimized design

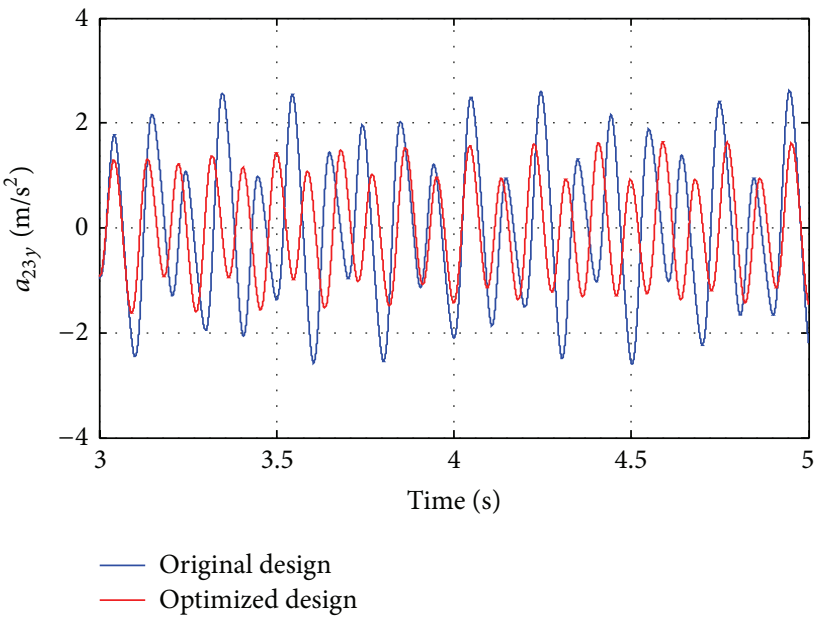

(b)

FIGURE 8: Responses of gear 23 in original and optimized designs. 


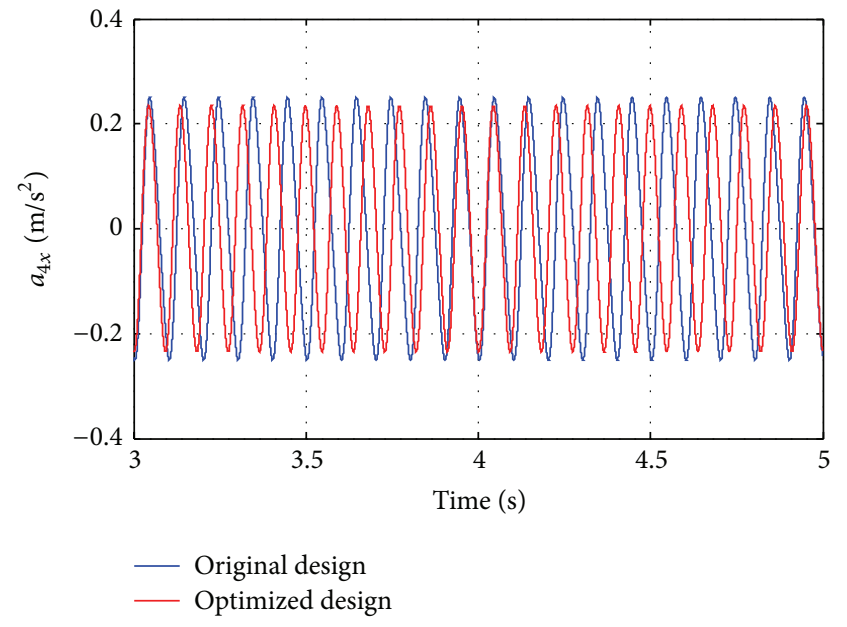

(a)

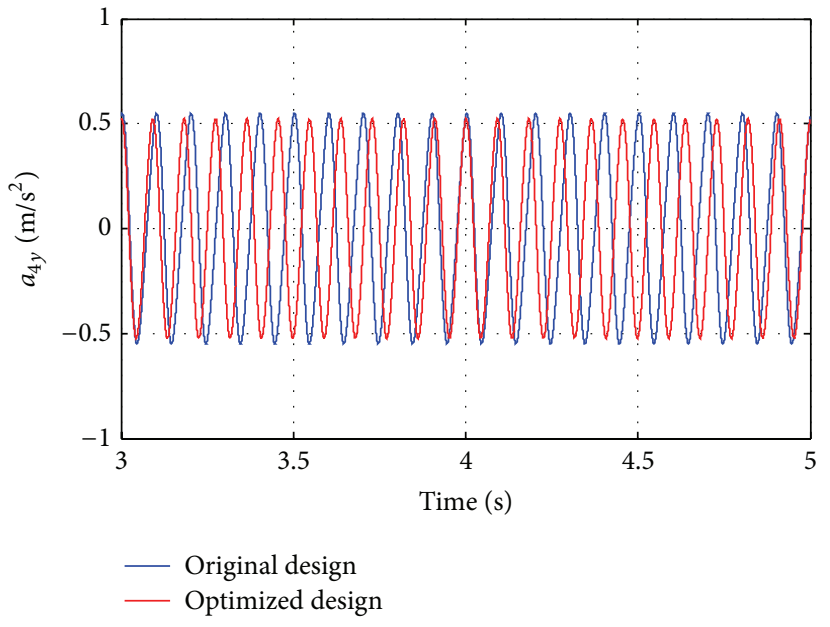

(b)

FIGURE 9: Responses of gear 4 in original and optimized designs.

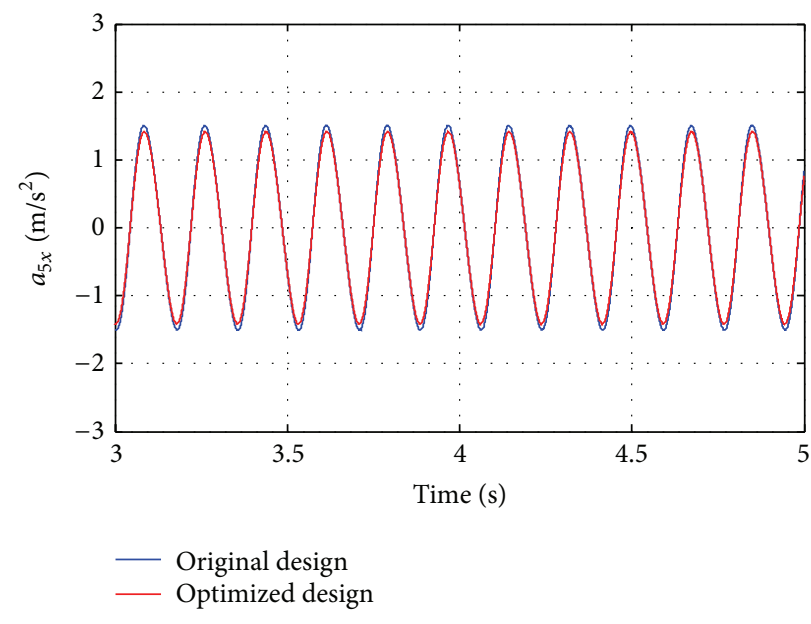

(a)

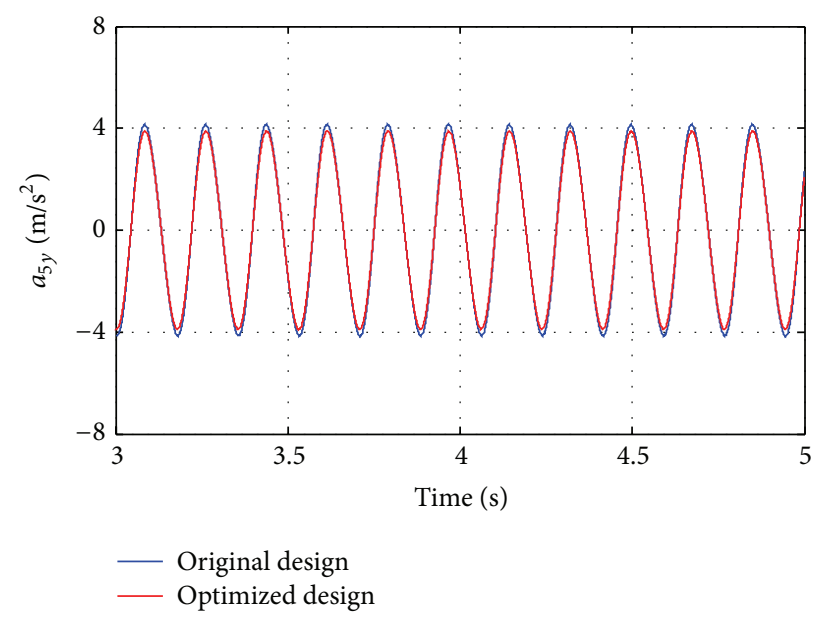

(b)

FIGURE 10: Responses of gear 5 in original and optimized designs.

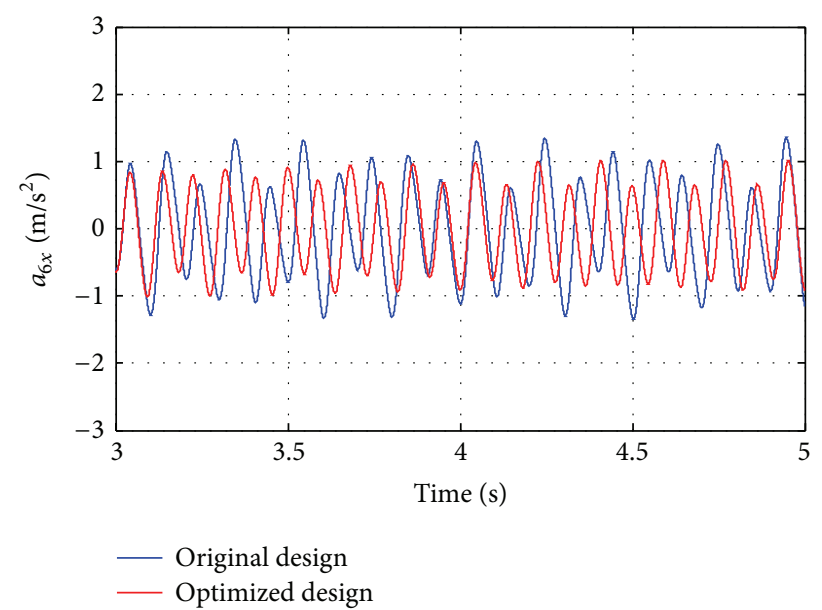

(a)

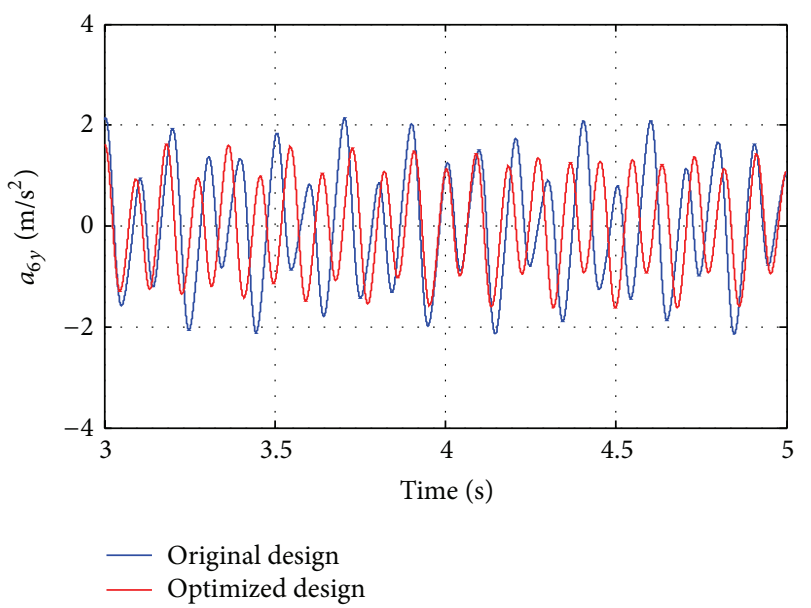

(b)

FIGURE 11: Responses of gear 6 in original and optimized designs. 
(2) The best compromise solution in Pareto optimal solutions is obtained by FST to avoid human preference. Compared with original design, the optimized design has better dynamic responses with minimum outer diameter, which indicate FST is beneficial for decision maker.

(3) The comparisons between response curves of original and optimized designs demonstrate that the response amplitudes become smaller and decay gets faster after optimization, which indicate that the optimization procedure is effective for the optimization of steering mechanism.

In conclusion, the proposed optimization procedure based on MNSGA-II and FST is feasible to solve the multiobjective optimization of gear train with mixed continuousdiscrete variables under nonlinear constraints. In addition, the procedure is flexible and can be extended to optimizations of other more complex mechanical structures.

\section{Nomenclature}

S:

gear 6 and eccentric axis of gear

$\theta_{i}: \quad$ Angular displacement of gear $i$

$x_{i}$ : $\quad$ Displacement of gear $i$ in $x$ direction

$y_{i}$ : $\quad$ Displacement of gear $i$ in $y$ direction

$x_{i j}: \quad$ Relative displacement of gears $i$ and $j$

$x_{n 3}, x_{n 4}$ : Profile modification coefficients of gears 3 and 4

$r_{b i}: \quad$ Radius of base circle of gear $i$

$K_{i j}(t)$ : Time-varying meshing stiffness between gears $i$ and $j$

$C_{i j}$ : $\quad$ Damping between gears $i$ and $j$

$K_{i x}, K_{i y}$ : Stiffness of gear $i$ in $x$ and $y$ directions

$C_{i x}, C_{i y}$ : Damping of gear $i$ in $x$ and $y$ directions

$T_{i}$ : $\quad$ Torque of DC servo motor $i$

$F$ : $\quad$ External excitation

M: $\quad$ Mass matrix

K: $\quad$ Stiffness matrix

C: $\quad$ Damping matrix

X: $\quad$ Displacement vector

P: $\quad$ Excitation vector

$m_{i}$ : Mass of gear $i$

$\omega_{m}$ : Meshing frequency

$\alpha: \quad$ Pressure angle

$\alpha_{34}$ : $\quad$ Meshing angle of gears 3 and 4

$I_{i}: \quad$ Inertia of gear $i$

$t: \quad$ Time

$z_{i}: \quad$ Teeth number of gear $i$

$\varepsilon_{i j}$ : $\quad$ Contact ratio of gears $i$ and $j$

$S_{a i}: \quad$ Thickness of gear $i$ at tip cylinder

$\tau$ : $\quad$ Meshing phase angle

$\zeta$ : $\quad$ Meshing damping coefficient

$\eta$ : $\quad$ Shaft damping coefficient

$a_{i x}, a_{i y}$ : Acceleration of gear $i$ in $x$ direction
D: $\quad$ Outer diameter of steering mechanism

$b_{i j}$ : Width of gears $i$ and $j$

$m_{i j}$ : Modulus of gears $i$ and $j$

$l_{1}, l_{2}$ : Location parameters of steering point and spherical roller bearing

$d$ : Outer diameter of mandrel

$\sigma_{H}:$ Maximum contact strength

$\left[\sigma_{H}\right]$ : Allowable contact stress

$a: \quad$ Centre distance of meshing pair

$i$ : Transmission ratio of meshing pair

$K_{d}$ : Dynamic load coefficient

$\sigma_{F}:$ Maximum bending strength

$\left[\sigma_{F}\right]$ : Allowable bending stress

$y_{F}$ : Tooth form factor

$\sigma_{\max }:$ Maximum bending stress of mandrel

$[\sigma]:$ Allowable bending stress of mandrel

$k$ : Build-up rate

$\beta$ : $\quad$ Steering angle of steering mechanism.

\section{Conflict of Interests}

The authors declare that there is no conflict of interests regarding the publication of this paper.

\section{Acknowledgment}

This work was sponsored by the Key Technologies R\&D Program of Tianjin under Grant no. 11ZCKFGX03500.

\section{References}

[1] M. Bozca, "Torsional vibration model based optimization of gearbox geometric design parameters to reduce rattle noise in an automotive transmission," Mechanism and Machine Theory, vol. 45, no. 11, pp. 1583-1598, 2010.

[2] W. Huang, L. Fu, X. Liu, Z. Wen, and L. Zhao, “The structural optimization of gearbox based on sequential quadratic programming method," in Proceedings of the 2nd International Conference on Intelligent Computing Technology and Automation (ICICTA '09), pp. 356-359, Hunan, China, October 2009.

[3] T. H. Chong, I. Bae, and A. Kubo, "Multiobjective optimal design of cylindrical gear pairs for the reduction of gear size and meshing vibration," JSME International Journal, Series C: Mechanical Systems, Machine Elements and Manufacturing, vol. 44, no. 1, pp. 291-298, 2001.

[4] H. Zarefar and S. N. Muthukrishnan, "Computer-aided optimal design via modified adaptive random-search algorithm," Computer-Aided Design, vol. 25, no. 4, pp. 240-248, 1993.

[5] M. Ciavarella and G. Demelio, "Numerical methods for the optimisation of specific sliding, stress concentration and fatigue life of gears," International Journal of Fatigue, vol. 21, no. 5, pp. 465-474, 1999.

[6] H.-Z. Huang, Z.-G. Tian, and M. J. Zuo, "Multiobjective optimization of three-stage spur gear reduction units using interactive physical programming," Journal of Mechanical Science and Technology, vol. 19, no. 5, pp. 1080-1086, 2005.

[7] M. Faggioni, F. S. Samani, G. Bertacchi, and F. Pellicano, "Dynamic optimization of spur gears," Mechanism and Machine Theory, vol. 46, no. 4, pp. 544-557, 2011. 
[8] B. A. Abuid and Y. M. Ameen, "Procedure for optimum design of a two-stage spur gear system," JSME International Journal, Series C: Mechanical Systems, Machine Elements and Manufacturing, vol. 46, no. 4, pp. 1582-1590, 2003.

[9] D. F. Thompson, S. Gupta, and A. Shukla, "Tradeoff analysis in minimum volume design of multi-stage spur gear reduction units," Mechanism and Machine Theory, vol. 35, no. 5, pp. 609627,2000

[10] F. Mendi, T. Başkal, K. Boran, and F. E. Boran, “Optimization of module, shaft diameter and rolling bearing for spur gear through genetic algorithm," Expert Systems with Applications, vol. 37, no. 12, pp. 8058-8064, 2010.

[11] T. H. Chong and J. S. Lee, "A design method of gear trains using a genetic algorithm," International Journal of the Korean Society of Precision Engineering, vol. 1, no. 1, pp. 62-70, 2000.

[12] C. Gologlu and M. Zeyveli, "A genetic approach to automate preliminary design of gear drives," Computers \& Industrial Engineering, vol. 57, no. 3, pp. 1043-1051, 2009.

[13] J. L. Marcelin, "Genetic optimisation of gears," International Journal of Advanced Manufacturing Technology, vol. 17, no. 12, pp. 910-915, 2001.

[14] O. Buiga and L. Tudose, "Optimal mass minimization design of a two-stage coaxial helical speed reducer with Genetic Algorithms," Advances in Engineering Software, vol. 68, pp. 2532, 2014.

[15] I. Ciglarič and A. Kidričc, "Computer-aided derivation of the optimal mathematical models to study gear-pair dynamic by using genetic programming," Structural and Multidisciplinary Optimization, vol. 32, no. 2, pp. 153-160, 2006.

[16] G. Bonori, M. Barbieri, and F. Pellicano, "Optimum profile modifications of spur gears by means of genetic algorithms," Journal of Sound and Vibration, vol. 313, no. 3-5, pp. 603-616, 2008.

[17] M. Barbieri, G. Bonori, and F. Pellicano, "Corrigendum to: optimum profile modifications of spur gears by means of genetic algorithms," Journal of Sound and Vibration, vol. 331, pp. 48254829, 2012.

[18] K. Deb, A. Pratap, S. Agarwal, and T. Meyarivan, "A fast and elitist multiobjective genetic algorithm: NSGA-II," IEEE Transactions on Evolutionary Computation, vol. 6, no. 2, pp. 182197, 2002.

[19] K. Deb and S. Jain, "Multi-speed gearbox design using multiobjective evolutionary algorithms," Transactions of the ASME, Journal of Mechanical Design, vol. 125, no. 3, pp. 609-619, 2003.

[20] R. C. Sanghvi, A. S. Vashi, H. P. Patolia, and R. G. Jivani, "Multi-objective optimization of two-stage helical gear train using NSGA-II," Journal of Optimization, vol. 2014, Article ID 670297, 8 pages, 2014

[21] B. Luo, J. Zheng, J. Xie, and J. Wu, "Dynamic crowding distance-a new diversity maintenance strategy for MOEAs," in Proceedings of the 4th International Conference on Natural Computation (ICNC '08), pp. 580-585, IEEE, Jinan, China, October 2008.

[22] Y. Z. Li, W. T. Niu, H. T. Li, Z. J. Luo, and L. N. Wang, "Study on a new Steerable mechanism for point-the-bit rotary steerable system," Advance in Mechanical Engineering, vol. 6, Article ID 923178, 14 pages, 2014.

[23] A. Kahraman, "Load sharing characteristics of planetary transmissions," Mechanism and Machine Theory, vol. 29, no. 8, pp. 1151-1165, 1994.
[24] J. Wei, C. Lv, W. Sun, X. Li, and Y. Wang, "A study on optimum design method of gear transmission system for wind turbine," International Journal of Precision Engineering and Manufacturing, vol. 14, no. 5, pp. 767-778, 2013.

[25] G. J. Yue, C. J. Bao, and S. F. Dong, "Optimization design of spur gear transmission," Coal Technology, vol. 31, no. 4, pp. 16-17, 2012 (Chinese).

[26] M. Gen and R. Cheng, Genetic Algorithms and Engineering Design, John Wiley \& Sons, Toronto, Canada, 1997.

[27] T. Ray, K. Tai, and K. C. Seow, "Multiobjective design optimization by an evolutionary algorithm," Engineering Optimization, vol. 33, no. 4, pp. 399-424, 2001. 


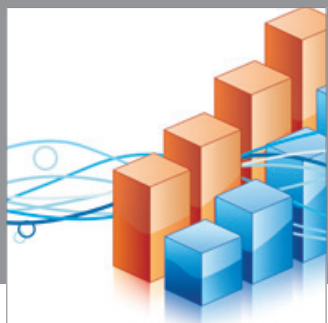

Advances in

Operations Research

mansans

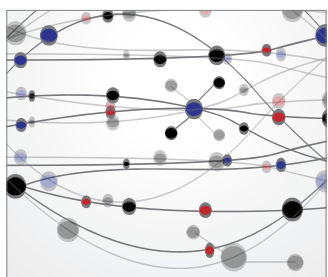

The Scientific World Journal
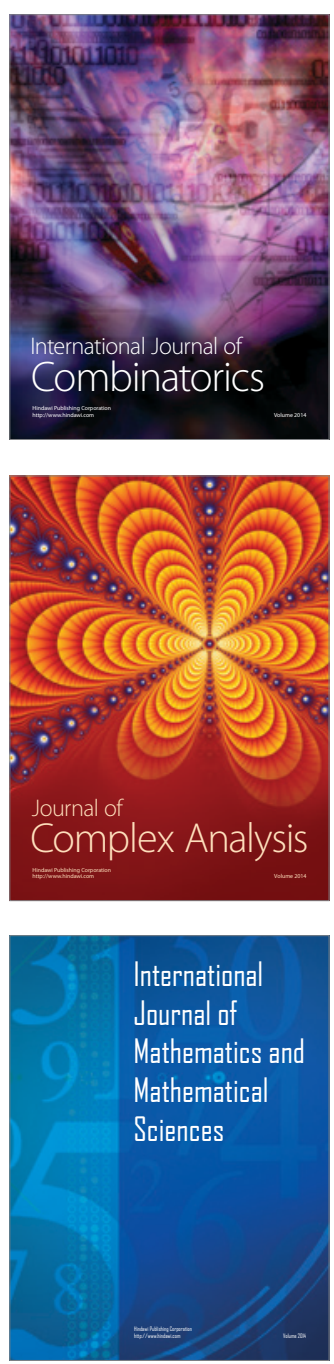
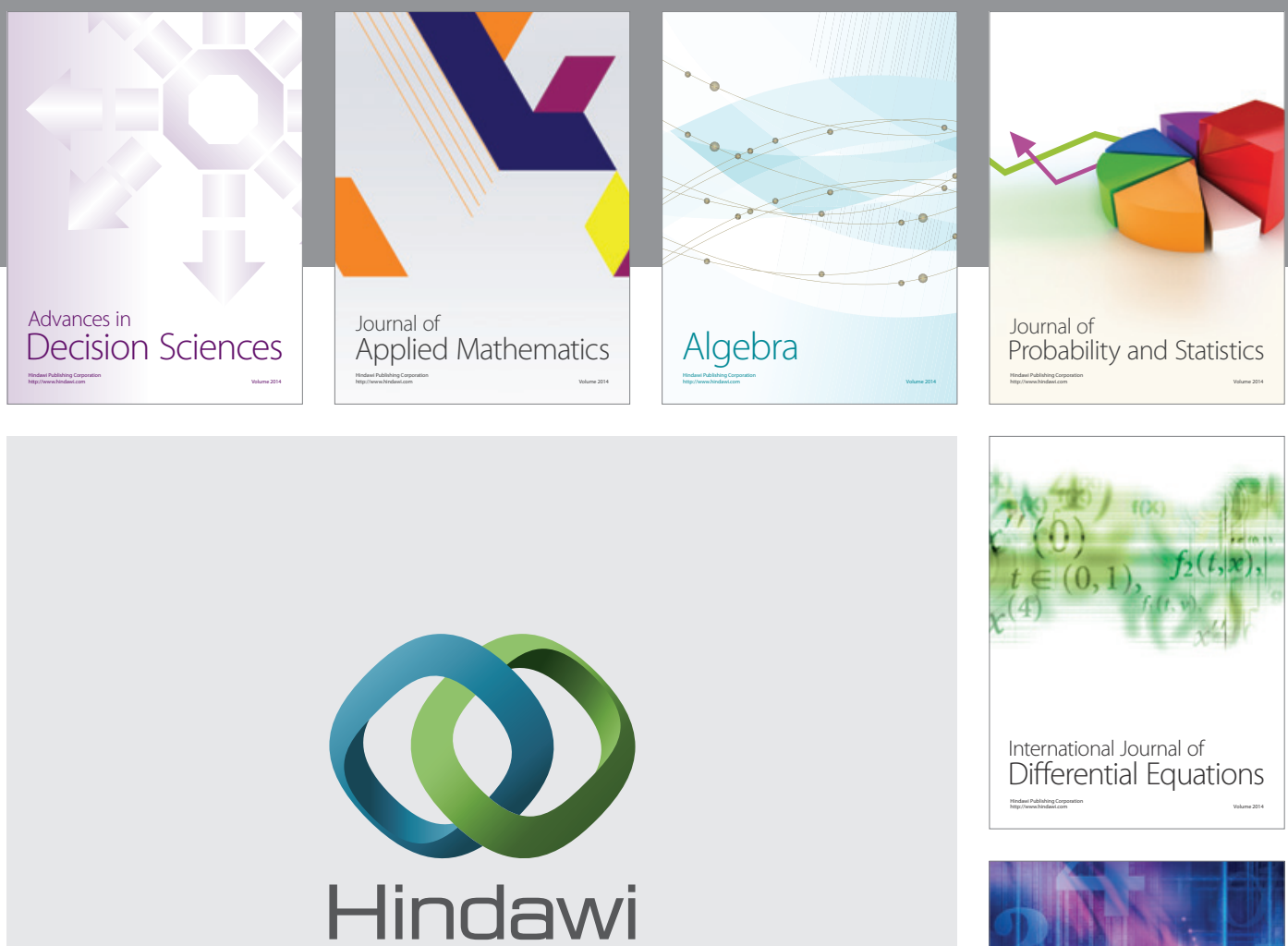

Submit your manuscripts at http://www.hindawi.com
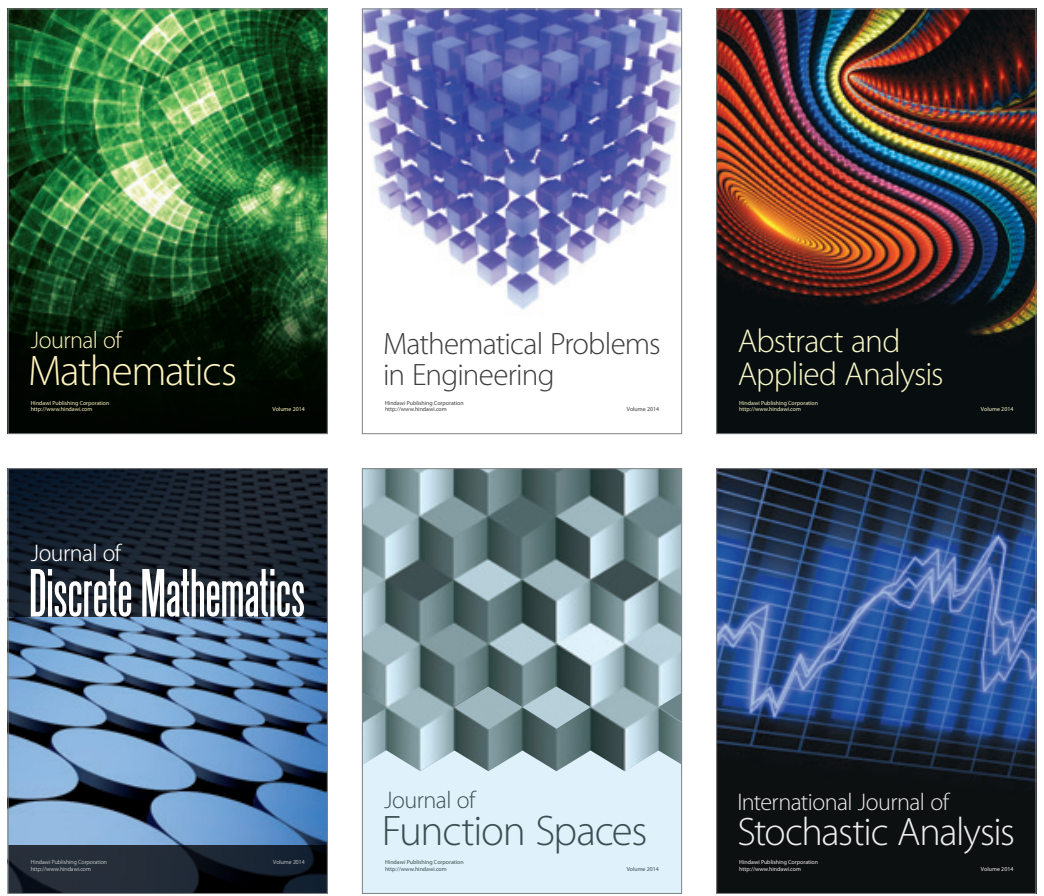

Journal of

Function Spaces

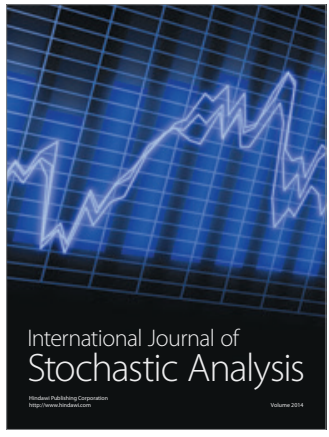

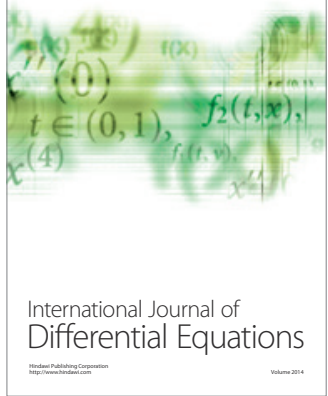
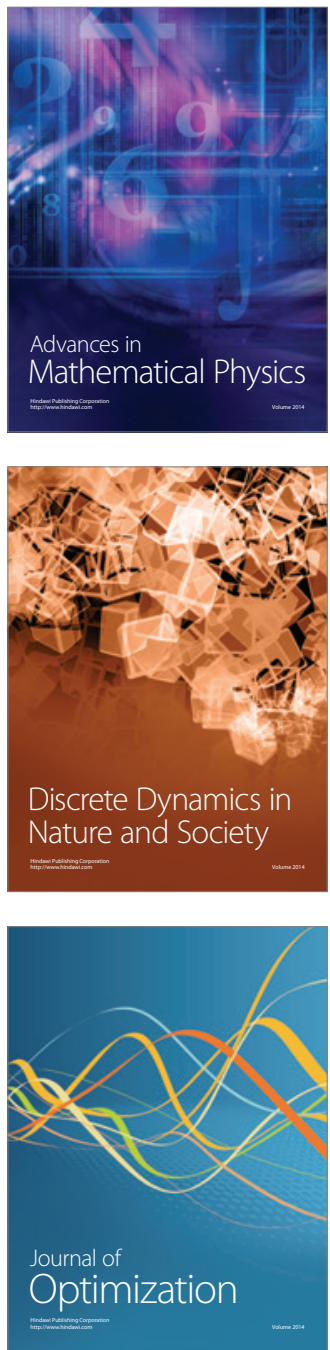